\title{
Thoracic and lumbar fractures in adolescents. An eight-year study
}

\author{
Félix Adolfo Sánchez-Chávez ${ }^{1}$ and Jorge Arturo Cabrera-Escamilla ${ }^{2}$
}

${ }^{1}$ Department of Spine Surgery, Hospital de Traumatología y Ortopedia No 21, Instituto Mexicano del Seguro Social (IMSS), Monterrey, N.L.; ${ }^{2}$ Department of Spine Surgery, Hospital de Traumatología Victorio de la Fuente Narváez, IMSS, Mexico City, Mexico

\begin{abstract}
Methods: In order to know the characteristics of these lesions in our environment and compare with those the adults, a transversal and descriptive study of adolescents between 12 and 18 years who were hospitalized for thoracic and lumbar fracture in two centers of high level trauma in our country for 8 years was performed. The variables studied were applied statistical analysis descriptive and correlation. Results: They were found significant date by associating the causes of damage with associated lesions $(p=0.006)$ and the initial neurological damage associated with the final neurological damage $(p=0.000)$. Discussion: They were registered seven teenagers with 10 fractures firearm, as rare cause of injury. An increase in the frequency of thoracic and lumbar fractures in adolescents with increasing age was found. The thoracic and lumbar fractures in adolescents caused by road accidents are associated with lesions in the chest and abdomen. And when are caused by falls are associated with lower extremity fractures. In addition, $13.5 \%$ of cases showed significant changes toward improvement in the initial neurological damage.
\end{abstract}

KEY WORDS: Thoracic fracture. Lumbar fracture. Fractures in adolescents.

\section{Introduction}

Damage to the vertebral column in pediatric patients is rare, with an incidence of 1 to $2 \%{ }^{1}$. It can occur isolated or associated with other type of damage, such as damage to the spinal cord, head injury, or in the limbs or other organs ${ }^{2}$. It is caused by high-energy trauma, as in road accidents and falls, but when it occurs in small children, child abuse should be suspected ${ }^{3,4}$. Spinal injury caused by firearm projectile (FAP), which is often seen in military populations, is currently showing an increase in civilian population, owing to easy access to firearms acquisition in an unauthorized or illegal form ${ }^{5,6}$. Nearly $32 \%$ of patients with neurological lesions associated with spine fracture are not diagnosed at the moment of injury, especially patients who have decreased level of consciousness owing to head injury and patients with associated damage to the pelvis and $\operatorname{limbs}^{7,8}$.
Computed tomography has replaced conventional $\mathrm{X}$-ray as the first-choice imaging technique in trauma patients, owing to its high diagnostic accuracy and cost-benefit ratio, which reduces excessive number of radiographies ${ }^{9-11}$. The vertebral column in children has more soft tissue and periosteum in comparison with adults, which results in higher potential for injury repair, bone remodeling, healing of damaged ligaments and neurological damage recovery ${ }^{12-14}$. A stable spinal fracture is a fracture with less than $20^{\circ}$ kyphotic deformity, less than $50 \%$ vertebral body height loss, with posterior column preservation and without neurological deficit ${ }^{15}$. Instability occurs when there is a fracture with progressive kyphosis of more than $20^{\circ}$, vertebral body height loss with damage of more than $50 \%$ and fragments in the spinal canal, associated with neurological deficiti ${ }^{16-18}$. Surgical stabilization of the fracture within the first 24 hours reduces rest-related complications $^{19}$, and the use of pedicle screws has been

\section{Correspondence:}

Date of reception: 05-08-2016

C.P. 64000 , Monterrey, N.L., México

E-mail: drfasanchez@ hotmail.com
Date of acceptance: 08-09-2016

DOI://dx.doi.org/10.24875/GMM.M18000054
Gac Med Mex. 2017;153:605-609

Contents available at PubMed www.gacetamedicademexico.com 
shown to be more effective as spinal fixation method both in children and in adults ${ }^{20}$. The thoracic region (T2-T10) constitutes the area of more involvement in children $^{21}$. The thoracolumbar junction (T12, L1 and L2) is the area mostly affected in adolescents and adults $^{22,23}$. The classifications proposed by Magerl and Frankel are adequate for spinal fracture morphopathological damage and associated neurological damage evaluation ${ }^{24-26}$.

The present study was carried out in order to know the characteristics of this type of injuries in our setting. We set forth as an objective to identify thoracic and lumbar fractures distinctive characteristics in adolescents and to identify differences with adults.

\section{Methods}

Adolescent patients of between 12 and 18 years of age, hospitalized at the department of vertebral column in two tertiary care centers, the High Specialty Medical Unit Hospital de Traumatología y Ortopedia No. 21 of the Mexican Institute of Social Security (IMSS - Instituto Mexicano del Seguro Social) in the city of Monterrey, Nuevo León, and the Hospital de Traumatología Victorio de la Fuente Narváez, of the IMSS in Mexico City, and who had been admitted with the diagnosis of thoracic and lumbar fracture between 2006 to 2013, were selected as sample. Descriptive and correlation statistical analyses were performed for the study variables using the SPSS statistical program, version 22. In addition to descriptive statistics, inferential or association statistical analysis was carried out using the nonparametric chi-square test to compare proportions, with statistically significant association being considered when the $p$-value was lower than 0.05 .

\section{Results}

Ninety-six adolescents were included, with predominance of the male gender being found in $66.7 \%$ of cases, with a mean age of $16.4 \pm 1.6$ years and a mode of 18 years (Fig. 1). The main cause of injury were falls from height in $57.3 \%$, followed by road accidents in $34.4 \%$. Rare causes were also found, such as FAP-associated spinal fractures in adolescents with $7.3 \%$ of cases (Fig. 2).

Spinal fracture-associated injuries occurred in 40 patients $(41.7 \%)$, with head trauma predominating in $12.5 \%$ and lower limb fractures in $10.4 \%$, while 56 patients $(58.3 \%)$ had no associated injuries (Table 1). Significant data were found by means of the $c^{2}$ statistical contrast analysis $\left(c^{2}=32.001 ; \mathrm{gl}=15\right.$; $p=0.006$ ) when the lesion cause was related to associated injuries. Spinal fractures produced by road accidents are significantly associated with thoracic and abdominal injuries. Spinal fractures produced by falls are significantly associated with harm to lower limbs (Table 2).

There were 64 cases recorded with fractures at a single level, 29 cases with fractures at two levels and 5 cases with fractures at three levels. The most commonly affected level was L1 in $29.2 \%$, followed by L2 in $12.5 \%$, T12 in $10.4 \%$ and L4 in $9.4 \%$ (Fig. 2). Magerl

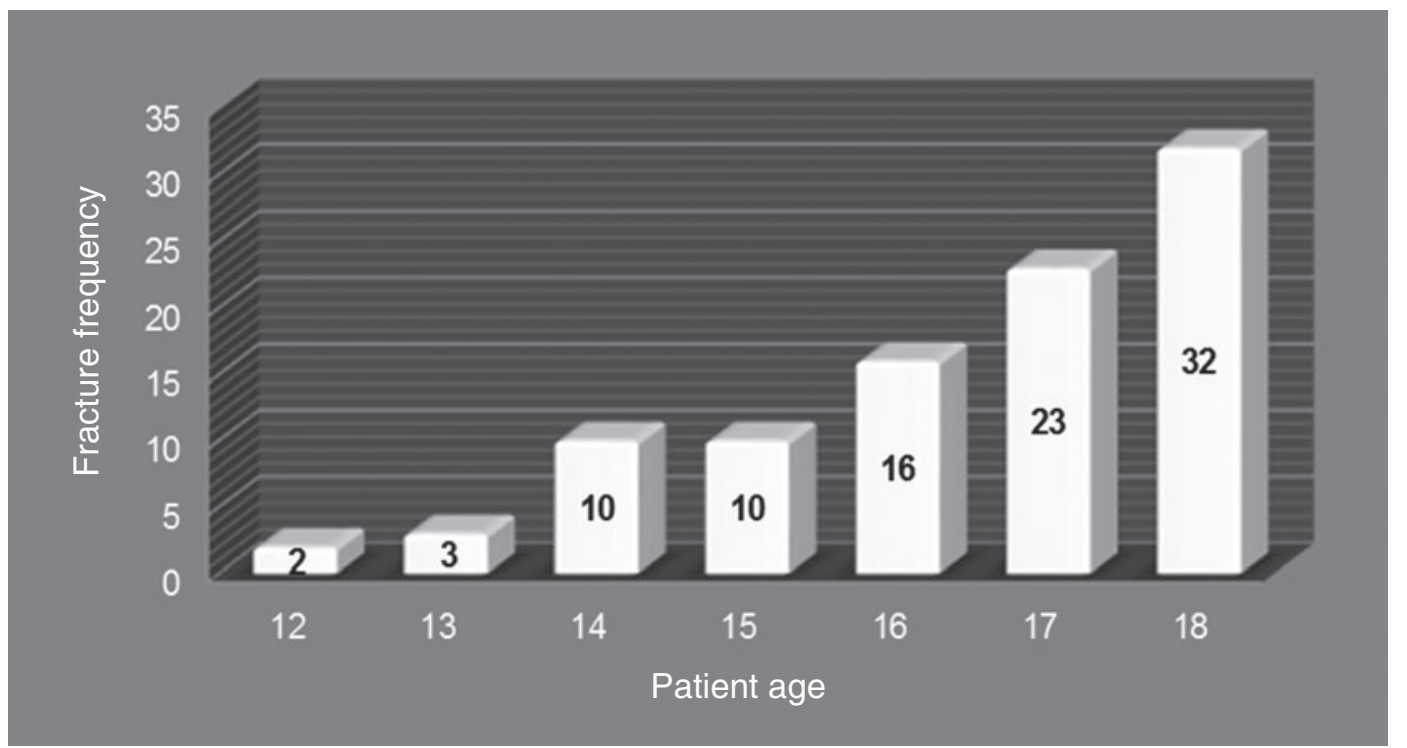

Figure 1. Distribution of fractures by age. 


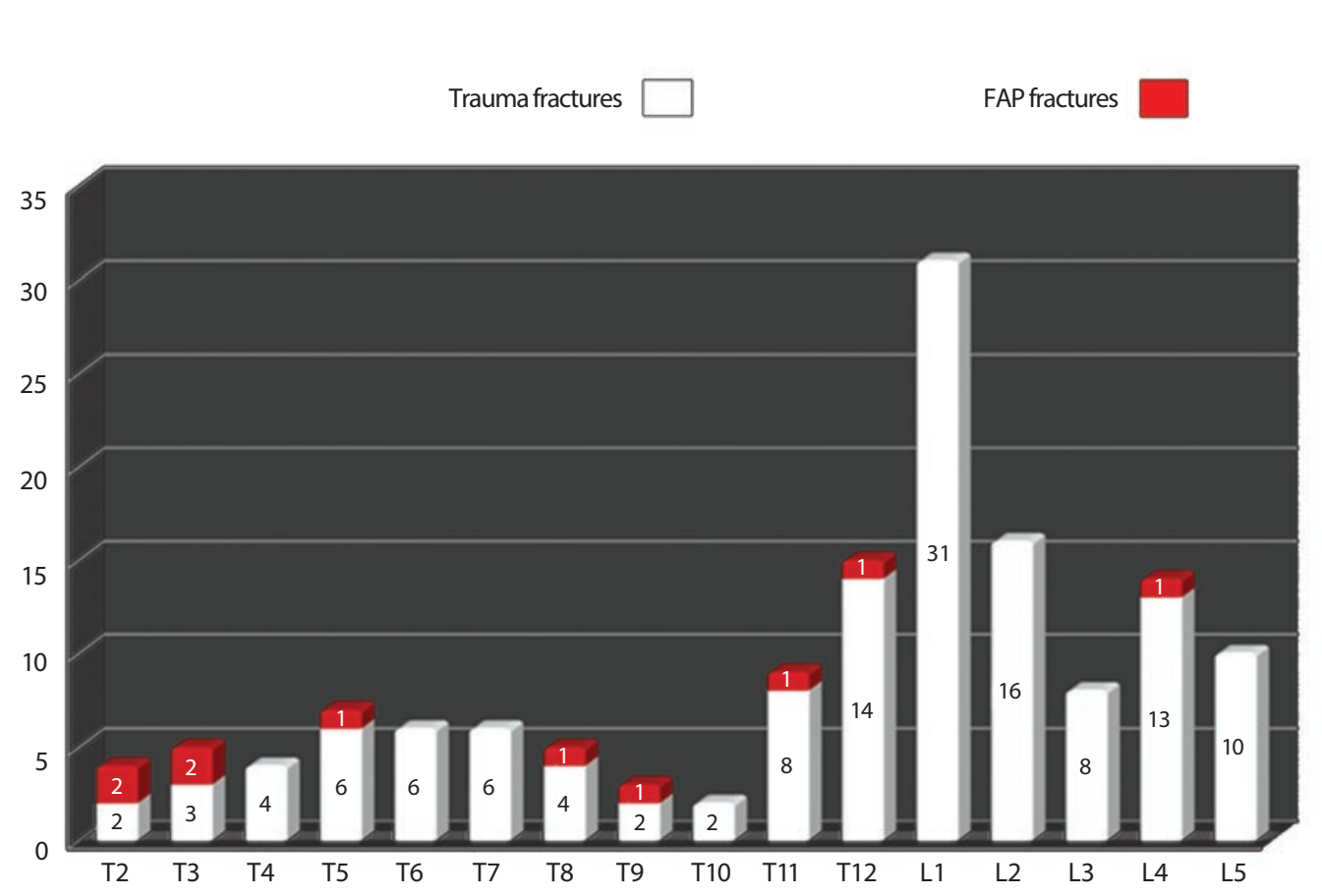

Figure 2. Distribution of fractures by level of involvement.

Table 1. Associated injuries

TRAUMATIC BRAIN INJURY

Traumatic brain injury

THORACIC INJURY

Rib fractures

Hemo-pneumothorax

Pneumothorax

ABDOMINAL INJURY

Spleen injury

Liver injury

Pelvis fracture

UPPER LIMB

Humerus fracture

Radioulnar fracture

Clavicle fracture+plexus injury

Radius fracture

LOWER LIMB

$\begin{array}{ll}\text { Femur fracture } & 1 \text { case } \\ \text { Tibiofibular fracture } & 2 \text { cases } \\ \text { Ankle fracture } & 4 \text { cases } \\ \text { Calcaneus fracture } & 2 \text { cases } \\ \text { Talus fracture } & 1 \text { case }\end{array}$

WITHOUT ASSOCIATED INJURY

12 cases

1 case

6 cases

2 cases

2 cases

2 cases

1 case

1 case

1 case

1 case

1 case
12 cases

9 cases

5 cases

10 cases

4 cases

(n)

type A injuries were found in $40.6 \%$ of patients, type B in $26 \%$ and type $C$ also in $26 \%$. Of a total of 135 spinal fractures in 96 patients, 125 were trauma fractures and 10 were FAP fractures. Eighty-six cases were treated with surgery and 10 were conservatively treated. Of the operated cases, $90.7 \%$ were resolved with a single posterior approach, $8.1 \%$ required posterior-anterior combined approach and $1.2 \%$ required a single anterior approach.

Spine fracture-associated neurological deficit occurred initially in 32 patients (33.3\%), while 64 cases $(66.6 \%)$ had no deficit. Twelve patients presented with complete spinal cord lesion or Frankel $A$, and 20 patients with intermediate lesions: Frankel B, 1 patient, Frankel C, 11 patients, and Frankel D, 8 patients. Once the injury or arthrodesis was consolidated, approximately 4 months after the fracture was treated, neurological deficit persisted in 21 patients $(21.9 \%)$, 11 with complete spinal cord lesion or Frankel $A$ and 10 with intermediate degrees of neurological injury: Frankel $C$ in 9 patients and Frankel $D$ in 1 patient. When statistical association tests were performed between the initial neurological damage variable and the final neurological damage variable, it was found to be highly significant $\left(c^{2}=159.037 ; g l=12 ; p=0.000\right)$ (Table 1). In 83 cases (86.5\%), the same results were identified at initial and final neurological evaluation. The remaining 13 cases (13.5\%) had significant neurological changes towards improvement. All seven FAP-wounded patients remained without changes 
Gaceta Médica de México. 2017;153

Table 2. Table of statistical association between variables

\begin{tabular}{|c|c|c|c|}
\hline Variables & $\psi^{2}$ test & Interpretation & \\
\hline Gender and age & $p=0.366$ & & $\infty$ \\
\hline Mechanism of injury and associated injuries & $p=0.006$ & $\begin{array}{l}\text { Road accidents are associated with thoracic and abdominal injuries } \\
\text { Falls are associated with lower limb injuries }\end{array}$ & 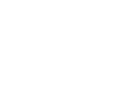 \\
\hline Mechanism of injury and gender & $p=0.501$ & & $\bar{E}$ \\
\hline Mechanism of injury and age & $p=0.551$ & & $\stackrel{1}{2}$ \\
\hline Initial and final neurological damage & $p=0.000$ & $\begin{array}{l}\text { In } 86 \% \text { of cases neurological evaluation doesn't change; it's the same a } \\
\text { initiation than at the end of it } \\
\text { In } 13.5 \% \text { of cases there are neurological evaluation changes towards in }\end{array}$ & treatment \\
\hline Injury classification and age & $p=0.076$ & & $\frac{.-1}{3}$ \\
\hline Single, double or triple injury and age & $p=0.999$ & & 등 \\
\hline
\end{tabular}

between the initial and final evaluations: Frankel $A$ in 3 patients, Frankel $C$ in 1 patient, Frankel $D$ in 1 patient and Frankel $\mathrm{E}$ in 2 patients.

\section{Discussion}

We describe the common occurrence of spine fracture-associated injuries in pediatric patients, since $41.7 \%$ of the study subjects had associated injuries, whereas the remaining $58.3 \%$ did not. An increase in the frequency of spinal fractures is observed in adolescents as age advances, as also Hofbauer et al. ${ }^{1}$ and Moller et al. ${ }^{2}$ refer.

When spinal fracture in adolescents is caused by a road accident, there is a high likelihood for abdomen and thorax-associated injuries to occur, whereas when fractures are caused by falls, there is a high likelihood for lower-limb-associated injuries to occur. Of note, 10 fractured vertebrae were found to be caused by FAP in seven adolescents of our series, which reflects the increased violence that is being experienced in large cities ${ }^{5,6}$.

Among the study patients who suffered initial neurological damage, $13.5 \%$ showed significant changes towards improvement, unlike to what occurs in adult patients. Children have great potential to recover from neurological damage ${ }^{14}$.

In the present study, no predominant type of injury was found, unlike in adults, in whom type-A injuries are predominant ${ }^{24}$. Only one case in our series had to be resolved with a single anterior approach; $90.7 \%$ of cases were resolved with a single posterior approach. Since the disk and ligaments absorb the forces applied to the bone, fractures with complete shattering are rarely seen in children ${ }^{19}$. Adolescents with thoracic and lumbar fractures can be treated like adults, but unlike them, the vast majority of fractures can only be treated with the posterior approach.

\section{Conflicts of interests}

The authors declare not having any conflicts of interests.

The investigation had no financial help or of any kind, and has no financial links with any company.

\section{References}

1. Hofbauer M, Jaindl M, Lee Hochtl L, et al. Spine injuries in polytraumatized pediatric patients: characteristics and experience from a level 1 trauma center over two decades. J Trauma Acute Care Surg. 2012; 73:156-61.

2. Moradi-Lakeh M, Rasouli M, Vaccaro A, et al. BMC Public Health. 2011; $11: 789$.

3. Jansson KA, Blomqvist $\mathrm{P}$, Svedmark $\mathrm{P}$, et al. Thoracolumbar vertebral fractures in Sweden: an analysis of 13,496 patients admitted to hospital. Eur J Epidemiol. 2010;25:431-7.

4. Habert J, Haller JO. latrogenic vertebral body compression fracture in a premature infant caused by extreme flexion during positioning for a lumbar puncture. Pediatr Radiol. 2000;30:410-1.

5. Jaiswal M, Mittal RS. Concept of gunshot wound spine. Asian Spine J. 2013;7:359-64.

6. Bordon G, Girona B. Gunshot wound in lumbar spine with intradural location of a bullet. Case Reports in Orthopedics. 2014; 1-4. Disponible en: http://dx.doi.org/10.1155/2014/698585.

7. De Amoreira RG, Nadal LG. Spinal cord trauma in children under 10 years of age: clinical characteristics and prevention. Childs Nerv Syst. 2012;28:1919-24.

8. Junkins EP, Stotts A, Santiago R, et al. The clinical presentation of pediatric thoracolumbar fractures: a prospective study. J Trauma. 2008; 65:1066-71.

9. Bensch FV, Kiuru MJ, Koivikko MP, et al. Spine fractures in falling accidents: analysis of multidetector CT findings. Eur Radiol. 2004;14:618-24.

10. Bensch FV, Koivikko MP, Koskinen SK. MDCT findings in sports and recreational accidents. Acta Radiologica. 2011;52:1107-12.

11. Jiménez RR, DeGuzmán NA, Shiran $S$, et al. CT versus plain radiographs for evaluation of $c$-spine in young children: do benefits outweigh risks? Pediatr Radiol. 2008;38:635-44.

12. Mortazavi MM, Dogan S, Civelek E, et al. Pediatric multilevel spine injuries: an institutional experience. Childs Nerv Syst. 2011;27:1095-100.

13. Sieradzki JP, Sarwark JF. Thoracolumbar fracture-dislocation in child abuse: case report, closed reduction technique and review of the literature. Pediatr Neurosurg. 2008;44:253-7.

14. Basu S. Spinal injuries in children. Frontiers in Neurology. 2012;3:1-15. Disponible en: http://www.frontiersin.org/SpinalcordMedicine/archive. 
15. Thomas KC, Lalonde F, ONeil J, et al. Multiple level thoracolumbar burst fractures in teenaged patients. J Pediatr Orthop. 2003;23:119-23.

16. Van der Roer N, de Lange ESM, Bakker FC, et al. Management of traumatic thoracolumbar fractures: a systematic review of the literature. Eur Spine J. 2005;14:527-34.

17. Van Goethem JW, Maes M, Ozsarlak O, et al. Imaging in spinal trauma. Eur Radiol. 2005;15:582-90.

18. Wang ST, Ma HL, Liu ChL, et al. Is fusion necessary for surgically treated burst fractures of the thoracolumbar and lumbar spine? Spine. 2006;31:2646-52

19. Pakzad H, Roffey DM, Knight $\mathrm{H}$, et al. Delay in operative stabilization of spine fractures in multitrauma patients without neurologic injuries: effects on outcomes. Can J Surg. 2011;54:270-6.

20. Mueller TL, Miller NH, Baulesh DM, et al. The safety of spinal pedicle screw in children ages 1 to 12 . Spine J. 2013;13:894-901.
21. Reddy SP, Junewick JJ, Backstrom JW. Distribution of spinal fractures in children: does age, mechanism of injury, or gender play a significant role? Pediatr Radiol. 2003;33:776-81.

22. Knop Ch, Kranabetter T, Reinhold M, et al. Combined posterior-anterior stabilization of thoracolumbar injuries utilising a vertebral body replacing implant. Eur Spine J. 2009;18:949-63.

23. Steinmetz MP, Resnick DK. Thoracolumbar fractures. Contemporary Neurosurgery 2006:28:1-6.

24. Aebi M. Classification of thoracolumbar fractures and dislocations. Eur Spine J. 2010;19(Suppl 1):S2-7.

25. Frankel HL, Hancock DO, Hyslop G, et al. The value of postural reduction in the initial management of closed injuries of the spine with paraplegia and tetraplegia. I. Paraplegia. 1969;7:179-92.

26. Moller A, Hasserius R, Besjakov J, et al. Vertebral fractures in late adolescence: a 27 to 41 year follow-up. Eur Spine J. 2006:15:1247-54. 